\title{
Electrokinetic Properties of Colloidal Zirconia Powders in Aqueous Suspension
}

\author{
Wen-Cheng J. Wei, ${ }^{*}+$ Sheng-Chang Wang, and Fang-Yuan Ho \\ Institute of Materials Science and Engineering, National Taiwan University, Taipei, Taiwan 106, Republic of China
}

\begin{abstract}
Pure zirconia, yttria, and three yttria-doped zirconia powders of submicrometer size have been dispersed in various aqueous solutions. The zeta potential $(\zeta)$ of the zirconia powders is determined primarily via streaming-current (SC) detection and is confirmed using electrophoretic spectroscopy techniques. The results reveal that the isoelectric point (IEP) of these zirconia powders is in the $\mathrm{pH}$ range of 5.6-7.2 and $\zeta$ is controlled primarily by the yttrium content of the zirconia powders and the type of electrolyte. In addition, the yttria content strongly affects the potential and SC in zirconia suspensions only at high solids contents $(>1$ vol\%). The electrokinetic data reveal that the surface of the yttria-doped tetragonal zirconia powder (TZP) can be modified via the adsorption of ionic molecules or polymeric species in the suspension. The adsorption of an anionic polymer can stabilize zirconia particles in a solution that is almost neutral or weakly basic (in the IEP range of pure $\mathrm{ZrO}_{2}$ ). The interaction of the zirconia and yttria particles with the electrolytes in an aqueous suspension will be discussed to reveal the roles of hydrated oxide formation and zirconia surface interaction with polymeric dispersants.
\end{abstract}

\section{Introduction}

$\mathrm{D}^{\prime}$ SPERSION of submicrometer- or nanometer-sized ceramic powders in aqueous solution is one of the key factors in understanding the behavior of fine ceramic particles; this characteristic is the primary property in the application of chemical mechanical polishing (CMP). ${ }^{1,2}$ The property is especially important for concentrated colloidal systems that are used to make structural parts. The slurry requires a consistent flow behavior, to prevent the sedimentation of heavy particles such as zirconia $\left(\mathrm{ZrO}_{2}\right)$ during filtration. For filtration through a colloidal route, the viscosity of the suspension system, which is prepared under different dispersion conditions, may change by several orders of magnitude. In addition, the density may vary throughout the thickness of the sediment. In fact, the surface characteristics of the particles and the chemistry of the solution control the dispersion conditions and the properties of the green and fired ceramics.

Electrostatic repulsion forces that are generated by common surface charges on the particles provide the sources of stabilization of the suspensions. Two other effects - steric hindrance and a combination of electrosteric repulsions - also can be responsible for the stabilization. The zeta potential $(\zeta)$ is the most prominent parameter used to describe the surface-force interaction and the stabilization behavior of the particles in the

C. F. Zukoski-contributing editor

Manuscript No. 190066. Received June 29, 1998; approved May 25, 1999.

Supported by the National Science Council of Taiwan (under Contract No. NSC86 2622-E-002-026R)

Member, American Ceramic Society

Author to whom correspondence should be addressed. suspensions. This potential is influenced by many factors, such as the powder source, ${ }^{3-5}$ the electrolyte concentration (ionic strength) ${ }^{3}$ the particle concentration and size, the solution $\mathrm{pH}^{6,7}$ and the state of hydration. ${ }^{8}$

Wernet and $\mathrm{Feke}^{4}$ reported that powder loading possibly drives the acidity of suspension toward the point of zero charge (PZC) and may result in diminished electrostatic stabilization. Thus, a highly loaded powder suspension ultimately forms an agglomeration. Two basic problems result from this condition. One problem is the hydration reaction of the powder surface with the solution, which is especially conspicuous in a suspension of fine powders and high levels of solids content. The other problem is that the stability of the suspension decreases at a high level of solids content.

Because of recent advances in high-strength, high-fracturetoughness, and other versatile applications, zirconia has become an important ceramic material. ${ }^{9,10}$ To produce a zirconia material with final sintered properties of high tetragonal-phase ( $t$-phase) content and uniform microstructure, it is preferable to start with a fine powder with an appropriate phase stabilizer. However, fine zirconia powder, especially doped with dissimilar oxides and over a high surface area, has a high probability of flocculation, because of unavoidable hydration reactions in aqueous solutions. ${ }^{4}$ To achieve a stable zirconia suspension, polymeric additives such as poly(acrylic acid) have been added to the solution ${ }^{11}$ to create a repulsive force between the particles. In addition, suspension stability also can be obtained via $\mathrm{pH}$ adjustment. Repulsive forces result from the $\zeta$ value in the particles, which protect fine particles from agglomeration and leads to a higher packing density in the sediment. The uniform and denser green parts generally possess good sintering behavior and mechanical properties.

Measurement of the surface potential of ceramic powders can be achieved using several techniques, such as laser light scattering, mass transport, and electrokinetic sonic methods (see Table I); each of these techniques measures the electrophoretic mobility of the ceramic particles in solution. However, the use of any visual spectroscopic techniques is limited by the transparency of the suspension, which requires a very low concentration of solid particles. Obviously, the potential result is applicable only for the prediction of the dispersive behavior in a suspension with a low solids concentration.

In addition to these techniques, the "streaming current" (SC) method was developed recently for characterization of the coagulation of dosage in water systems. The fundamental theory of the SC method has been reported in previous literature, ${ }^{12}$ which conducted the testing in a capillary device. Recently, Dentel and co-workers ${ }^{12,13}$ changed the capillary device to a so-called "SC detector device," which could be used to measure suspensions with various solids contents. Those researchers reported a relationship that was different from the theoretical prediction: ${ }^{12}$

$$
I=-\left(\frac{16 \pi \eta \omega s R^{2}}{c^{2}}\right) \mathrm{EM}=-\left[4 \varepsilon \omega s\left(\frac{R^{2}}{c^{2}}\right)\right] \zeta
$$

where $s, c$, and $R$ are the piston stroke distance, width of the annulus, and the radius of geometrical properties of the SC 
Table I. Isoelectric Point (IEP) of Zirconia and Yttria Powders, as Reported in the Literature

\begin{tabular}{|c|c|c|c|c|}
\hline Material & Dispersion conditions & Measurement method & IEP & Reference \\
\hline $\begin{array}{l}m-\mathrm{ZrO}_{2} \\
3 \mathrm{Y}-\mathrm{TZP}\end{array}$ & $30 \mathrm{wt} \%$ solids & Zeta potential & 6 & Moreno et al. $^{3}$ \\
\hline $8 \mathrm{~m}^{2} / \mathrm{g}, 0.3 \mu \mathrm{m}^{\dagger}$ & $30 \mathrm{wt} \%$ solids & Zeta potential & 5 & Moreno et $\mathrm{al}^{3}{ }^{3}$ \\
\hline $13.1 \mathrm{~m}^{2} / \mathrm{g},{ }^{\dagger} 0.27 \mu^{\ddagger}$ & $15 \mathrm{wt} \%$ solids & $\begin{array}{l}\text { Electrokinetic sonic } \\
\text { amplitude (ESA) }\end{array}$ & 7.7 & Huisman et al. ${ }^{10}$ \\
\hline $\begin{array}{l}2.8 \mathrm{Y}-\mathrm{TZP}\left(40.4 \mathrm{~m}^{2} / \mathrm{g},{ }^{\dagger}\right. \\
\left.20 \mathrm{~nm}^{\ddagger}\right)\end{array}$ & & Zeta potential & 6.5 & Shan and Zhang ${ }^{14}$ \\
\hline$m-\mathrm{ZrO}_{2}$ & $\begin{array}{l}50 \mathrm{wt} \% \text { solids }+0.001 M \\
\mathrm{NaCl}\end{array}$ & Yield stress & 6.7 & Leong and co-workers ${ }^{6,7}$ \\
\hline$m-\mathrm{ZrO}_{2}$ & $\begin{array}{l}50 \text { wt } \% \text { solids }+0.00033 M \\
\mathrm{Na}_{2} \mathrm{SO}_{4}\end{array}$ & Yield stress & 5.0 & Leong and co-workers ${ }^{6,7}$ \\
\hline $\mathrm{Y}-\mathrm{ZrO}_{2}$ & $65 \mathrm{wt} \%$ solids & Yield stress & $7.5-8$ & Leong and co-workers ${ }^{6,7}$ \\
\hline$m-\mathrm{ZrO}_{2}$ & $\begin{array}{l}57 \text { wt } \% \text { solids }+0.3 \text { wt } \% \\
\text { Dispex A40 }\end{array}$ & Yield stress & 4 & Leong and co-workers ${ }^{6,7}$ \\
\hline $\mathrm{ZrO}_{2}\left(15.1 \mathrm{~m}^{2} / \mathrm{g}^{\dagger}\right)$ & 18 vol\% solids & Yield stess & 7.0 & Leong and co-workers ${ }^{6,7}$ \\
\hline $\mathrm{Y}_{2} \mathrm{O}_{3}$ & & Electrophoretic mobility & $8.8^{\S}$ & Kagawa et l. $^{8}$ \\
\hline $\mathrm{ZrO}_{2}$ & & Electrophoretic mobility & 6.5 & Kagawa et al. ${ }^{8}$ \\
\hline 3Y-TZP & & Electrophoretic mobility & 7.7 & Kagawa et al. $^{8}$ \\
\hline$m-\mathrm{ZrO}_{2}$ & 0.02 vol $\%$ & Electrophoretic mobility & 5.6 & Present work \\
\hline $\mathrm{Y}_{2} \mathrm{O}_{3}$ & 0.02 vol $\%$ & Electrophoretic mobility & 8.2 & Present work \\
\hline 3Y-TZP & 0.03 vol $\%$ & Electrophoretic mobility & $6.6-7.2$ & Present work \\
\hline 4Y-TZP & $0.03 \mathrm{vol} \%$ & Electrophoretic mobility & $6.6-7.2$ & Present work \\
\hline 6Y-TZP & 0.03 vol\% & Electrophoretic mobility & $6.6-7.2$ & Present work \\
\hline 3Y-TZP & 0.03 vol $\%$ & Streaming current & 6.6 & Present work \\
\hline 3Y-TZP & $1 \mathrm{vol} \%+1 \mathrm{wt} \% \mathrm{D}-134$ & Streaming current & 3.9 & Present work \\
\hline
\end{tabular}

${ }^{\S}$ Specific surface area. ${ }^{*}$ Particle size. ${ }^{8}$ In the form of $\mathrm{Y}(\mathrm{OH})_{3}$.

detector (SCD) cell, respectively. EM is the electrophoretic mobility. The driving speed of the motor is represented by $\omega$, and the viscosity is represented by $\eta$ (refer to Fig. A1(a) in the Appendix for an explanation of the variables). However, measurement of a buffered kaolinite suspension obviously revealed an offset from the origin (an intercept with the SC axis at a negative unit) and a nonlinear relationship of greater negative mobility, as well as a deviation from the linear currentpotential $(I-\zeta)$ relationships that are predicted by Eq. (1). Dentel et al. ${ }^{12}$ suggested that this phenomenon is due to the negative charge of the sensor surfaces (which are composed of a plastic material), which may not be completely covered by charged particles.

The surface potential of a submicrometer-sized zirconia powder is related to the surface reactions of the zirconium and hydroxyl species $(\mathrm{Zr}-\mathrm{OH})$. The protonization $(\mathrm{j} 1)^{\ddagger}$ or deprotonization $(\mathrm{j} 2)^{\S}$ of a hydrated $\mathrm{Zr}-\mathrm{OH}$ unit proceeds toward the equilibrium condition of the PZC. This condition reveals that

$$
\mathrm{PZC}=\frac{1}{2}\left(\mathrm{p} K_{\mathrm{j} 1}+\mathrm{p} K_{\mathrm{j} 2}\right)
$$

where $K_{\mathrm{j} 1}$ and $K_{\mathrm{j} 2}$ are defined as the equilibrium constants of the surface ionization reactions $\mathrm{j} 1$ and $\mathrm{j} 2$, respectively. PZC values of $6.5 \pm 0.1$ have been reported. ${ }^{4}$ Furthermore, the surface potential of various $\mathrm{ZrO}_{2}$ and yttria $\left(\mathrm{Y}_{2} \mathrm{O}_{3}\right)$ powders have been measured and reported using one characteristic parameter of these powders: the isoelectric point (IEP). The IEP values that have been reported in the literature and summarized in Table I are in the range of 5.0-8.0; these values are clearly different from the theoretical value.

The coagulation of particles in a concentrated $\mathrm{ZrO}_{2}$ suspension is a very pronounced phenomenon that greatly influences the stability of the suspension. Therefore, the surface potential must be determined, to reveal the differences in the ceramic particle behavior at various concentrations. In this study, $\zeta$ and the $\mathrm{SC}$ readings of $\mathrm{ZrO}_{2}, \mathrm{Y}_{2} \mathrm{O}_{3}$, and yttria-doped tetragonal

\footnotetext{
$\stackrel{\ddagger}{\mathrm{MOH}_{2(\text { surf })}} \stackrel{K_{\mathrm{j} 1}}{\longrightarrow} \mathrm{MOH}_{(\text {surf })}+\mathrm{H}^{+}$

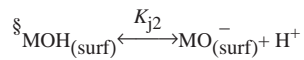

zirconia polycrystal (Y-TZP) suspensions at different $\mathrm{pH}$ values were measured. The yttria, which is in a hydrated form $\left(\mathrm{Y}(\mathrm{OH})_{3}\right)$, exhibits an IEP value of $8.8 ;^{8}$ this IEP value is not equal to that of that $\mathrm{ZrO}_{2}$. The influence of yttria in the form of a solid solution in Y-TZP powder is significant. In addition, suspensions that have been treated with various polymeric dispersants and electrolyte concentrations have been prepared, to investigate the behavior of these TZP powders and their interaction with dissimilar molecules in aqueous solution.

\section{Experimental Procedure}

In this study, four commercial-grade zirconia powderspure $\mathrm{ZrO}_{2}$ and $\mathrm{ZrO}_{2}$ that has been doped with 3, 4, and $6 \mathrm{~mol} \%$ $\mathrm{Y}_{2} \mathrm{O}_{3}$ (3Y-TZP, 4Y-TZP, and 6Y-TZP, respectively) (Tosoh Manufacturing Co., Ltd., Tokyo, Japan)—were used. The particle sizes of all the powders were $\sim 0.3 \mu \mathrm{m}$; however, the specific surface areas of the pure $\mathrm{ZrO}_{2}$ and $3 \mathrm{Y}$-TZP, 4Y-TZP, and 6Y-TZP powders were $15.5,15.7,17.9$, and $19.0 \mathrm{~m}^{2} / \mathrm{g}$, respectively. In addition, a high-purity $\mathrm{Y}_{2} \mathrm{O}_{3}$ powder $(99.99 \%$ pure, -325 mesh; Cerac, Milwaukee, WI) was used, for comparison between the TZP powders.

Two techniques were used to measure the $\zeta$ value of the suspensions. A photon correlation spectrometer (Model Zetasizer IIC, Malvern Instruments, Southborough, MA) and an electrokinetics charger analyzer (Model ECA2000 Chemtrac Systems, USA) were used to measure the $\zeta$ and SC values, respectively. Deionized water with a resistivity of $>15 \mathrm{M} \Omega \cdot \mathrm{cm}$ was used to prepare the suspensions.

The solution acidity $\left(\mathrm{pH}_{\mathrm{i}}\right)$ was $\mathrm{pH}=3-11$; the solutions were titrated with reagent-grade hydrochloric acid $(\mathrm{HCl})$ and sodium hydroxide $(\mathrm{NaOH})$. The temperature of all the suspensions was maintained constant at $26^{\circ}-27^{\circ} \mathrm{C}$. Unless specified in the text, $0.01 \mathrm{M}$ sodium chloride $(\mathrm{NaCl})$ was added in all the suspensions to maintain the same ionic strength prior to adding the powders. The suspensions always were dispersed in an ultrasonic bath (Model RK103, Bandelin Sonorex, Berlin, Germany) for $10 \mathrm{~min}$ and/or aged for $24 \mathrm{~h}$ before testing. The suspension $\mathrm{pH}_{0}$ and $\mathrm{pH}_{\mathrm{f}}$ values were measured; these represent the $\mathrm{pH}$ values after $10 \mathrm{~min}$ of ultrasonication and $24 \mathrm{~h}$ of aging, respectively. Normally, suspensions with a solids content of either 200 or $300 \mathrm{ppm}$ were prepared to measure the electrophoretic mobility. 

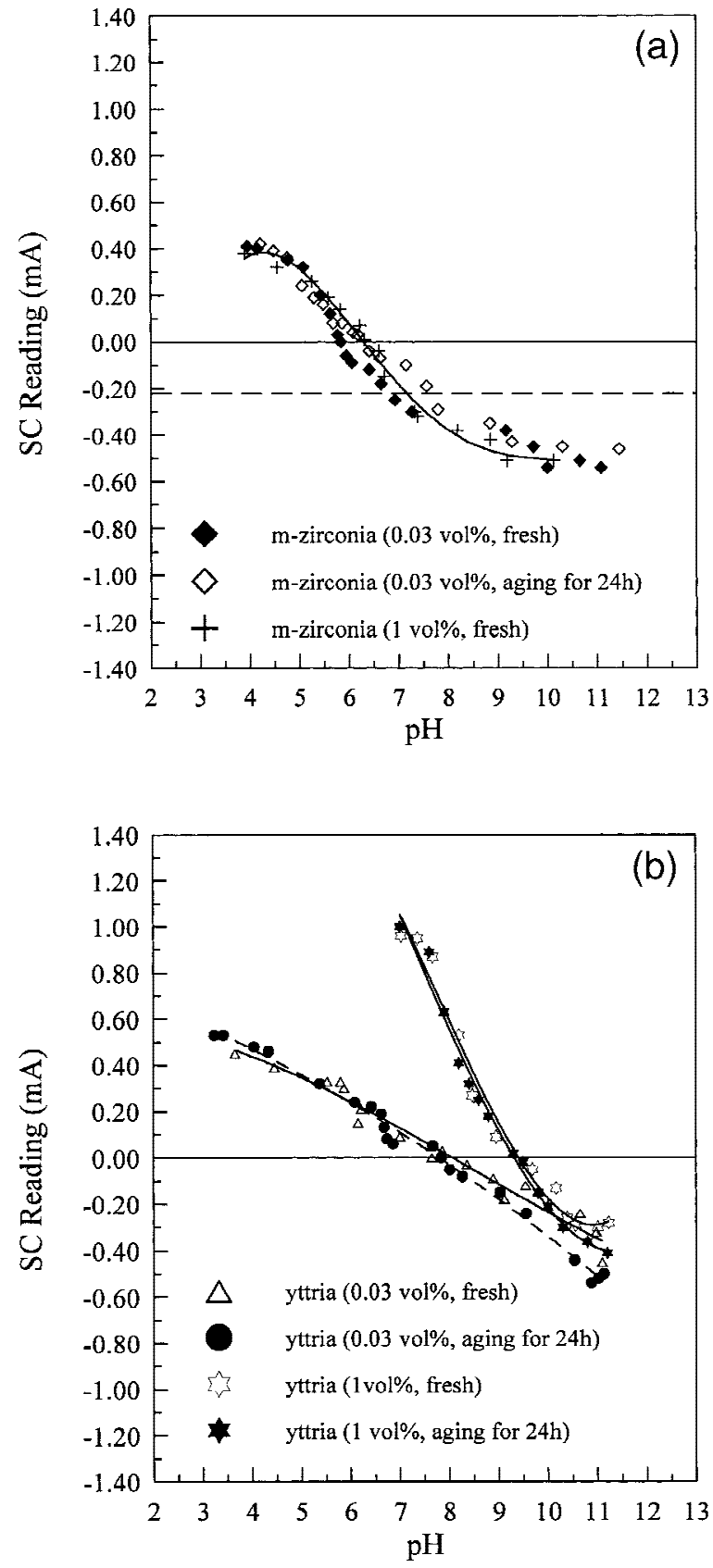

Fig. 1. Streaming-current (SC) readings of (a) pure $\mathrm{ZrO}_{2}$ and (b) $\mathrm{Y}_{2} \mathrm{O}_{3}$ plotted against the suspension $\mathrm{pH}$ under various specified conditions.

For SC measurement, suspensions with solids contents of 0.03 , 0.1 , and 1 vol\% were dispersed via turbomixing for $18 \mathrm{~h}$ and then aged for $24 \mathrm{~h}$.

To investigate the stability of the $3 \mathrm{Y}$-TZP suspensions, two organic surfactants were used: Ceramo D-134 (Dai-ichi Kogyo Seriyaku Co., Ltd., Japan), which is an ammonium salt of homopolymer of 2-propenoic acid, and B515.1 (Chartwell International, USA), which is an acidic metal-organic polymer of the amino group. The SC of TZP suspensions with 0-10 mol\% (based on the mass of solids content) of dispersant D-134 or B515.1 was measured. However, only the concentration of adsorbed D-134 polymer was determined, via measurement of the residual carbon content in the solution using the total organic content (TOC) technique (Model TOC 5000C, Shimadzu Co., Kyoto, Japan). The amount of dispersant D-134 that was adsorbed on the TZP powder could be determined indirectly.

\section{Results}

\section{(1) Electrokinetic Properties of Zirconia and Yttria Powders}

The relationship between the $\mathrm{pH}$ values (either $\mathrm{pH}_{0}$ or $\mathrm{pH}_{\mathrm{f}}$ ) and the $\mathrm{SC}$ readings of pure $\mathrm{ZrO}_{2}$ and $\mathrm{Y}_{2} \mathrm{O}_{3}$ is illustrated in Fig. 1. The $\mathrm{SC}$ reading of pure $\mathrm{ZrO}_{2}$ apparently does not change during aging for $24 \mathrm{~h}$; however, it does change for pure $\mathrm{Y}_{2} \mathrm{O}_{3}$. The SC curves show that the behavior of pure $\mathrm{ZrO}_{2}$ powder in a higher solids concentration $(1 \mathrm{vol} \%)$ is almost identical to that of the diluted suspension. The zero SC reading of pure

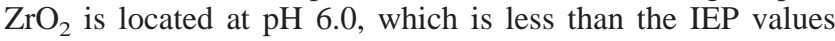
(6-6.7) that have been reported in the literature (Table I).

The SC curves of the yttria suspension (Fig. 1(b)) are greatly different at various solids contents, especially under acidic conditions. The literature has reported that yttria is in a hydrated form $\left(\mathrm{Y}(\mathrm{OH})_{3}\right)$ under aqueous conditions and exhibits an IEP value of 8.8. ${ }^{8}$ We have observed that ultrasonication for $10 \mathrm{~min}$ in a water bath is sufficient for $\mathrm{Y}_{2} \mathrm{O}_{3}$ to transform to a hydrated surface. The $\mathrm{pH}$ of the suspensions with high solid $\mathrm{Y}_{2} \mathrm{O}_{3}$ contents changed from being weakly acidic to neutral (for instance, $\mathrm{pH}_{\mathrm{i}}=4$ changed to $\mathrm{pH}_{0}=8$ ). The zero $\mathrm{SC}$ reading of the $\mathrm{Y}_{2} \mathrm{O}_{3}$ powder is located at $\mathrm{pH} 7.8$ in a diluted suspension; however, at $\mathrm{pH} 9.3$, the $\mathrm{Y}_{2} \mathrm{O}_{3}$ content in the suspension increased from $0.03 \mathrm{vol} \%$ to $1.0 \mathrm{vol} \%$.

The $\zeta$ value of the $3 \mathrm{Y}-\mathrm{TZP}, 4 \mathrm{Y}-\mathrm{TZP}$, and $6 \mathrm{Y}-\mathrm{TZP}$ powders that are dispersed in water at various $\mathrm{pH}$ values was measured using electrophoretic spectroscopy (Zetasizer IIC), as shown in Fig. 2. Based on the present results, the $\zeta$ values of the three TZP suspensions are very similar to each other. The IEP value of these TZP suspensions is in the $\mathrm{pH}$ range of 6.6-7.2 and does not seem to increase with changes in the $\mathrm{Y}_{2} \mathrm{O}_{3}$ content.

The streaming current $(I)$ of the three TZP suspensions in Fig. 2 was tested and compared to the $\zeta$ value in Fig. 2. Each $I-\zeta$ data pair is plotted in Fig. 3. Note that the data points for the basic conditions $(\mathrm{pH}>9)$ are not included in Fig. 3, because of the possible deviation of the SC reading at greater negative values. ${ }^{11}$ Figure 3 clearly shows a linear, but offset, relationship with the origin of the $I-\zeta$ diagram. The zero potential $(\zeta=$ 0 ) is located at $I=-0.22 \mathrm{~mA}$. Then, the IEP of the monoclinic zirconia $\left(m-\mathrm{ZrO}_{2}\right)$ suspensions in Fig. 1 can be determined

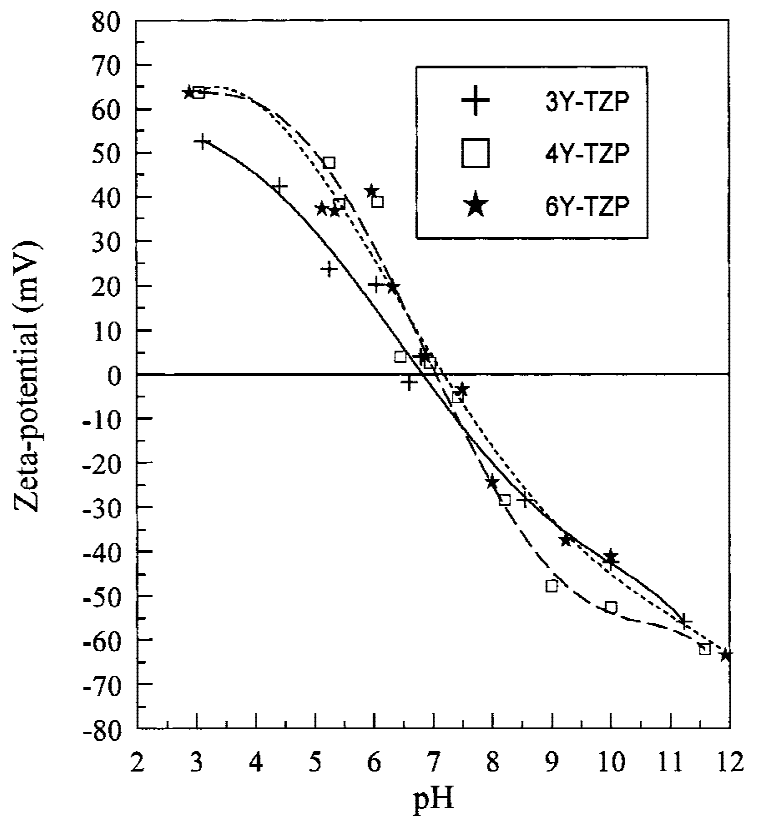

Fig. 2. Zeta potential $(\zeta)$ of three yttria-doped zirconia (Y-TZP) powders, versus the $\mathrm{pH}$ of aged solutions with a solids content of 0.03 $\mathrm{vol} \%$ and a $\mathrm{NaCl}$ concentration of $0.01 \mathrm{M}$. 


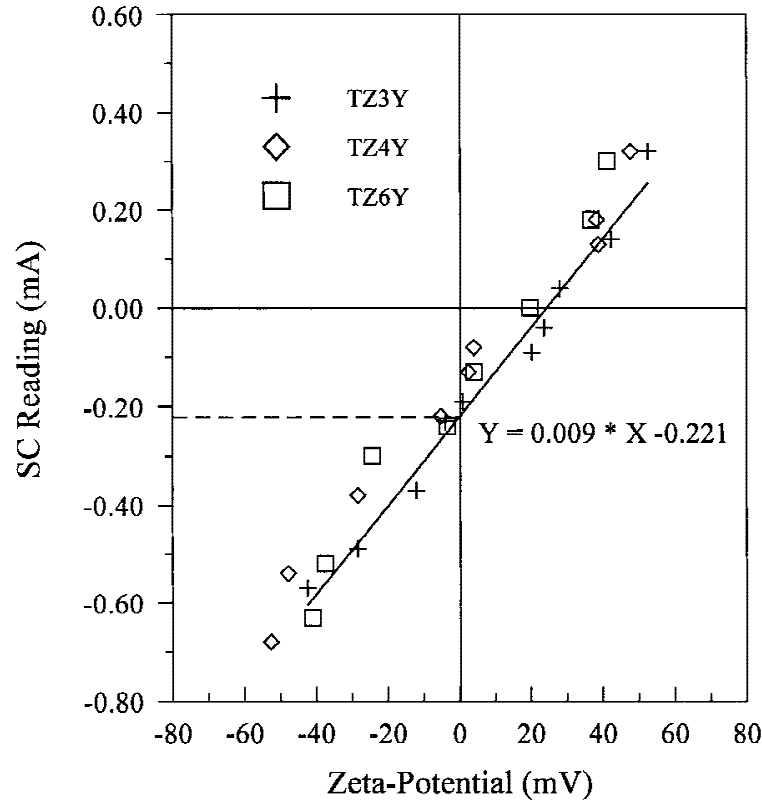

Fig. 3. Streaming-current (SC) reading versus the zeta potential $(\zeta)$ of the Y-TZP powders. Note that $\zeta=0$ corresponds to an SC reading of $-0.221 \mathrm{~mA}$ for the suspensions with a solids content of $0.03 \mathrm{vol} \%$.

using the $I-\zeta$ calibration curve in Fig. 3 . The IEP of the pure $\mathrm{ZrO}_{2}$ powder is located in the $\mathrm{pH}$ range of 7.0-7.4. Meanwhile, it is proposed in the Appendix that the linear offset results from the negative charge of the cell surface of the plastic (polytetrafluoroethylene, PTFE) driver (the ECA2000 electrokinetic charge analyzer) and also is related to the concentration of charged particles in the testing suspension. The fundamentals of the offset are discussed in the Appendix.

\section{(2) Reactions of TZP in Various Solids Concentrations}

The reactions of 3Y-TZP powder were investigated by measuring the $\mathrm{pH}$ change of the solution. Three series of suspensions, with $3 \mathrm{Y}-\mathrm{TZP}$ concentrations of $0.03,0.1$, and $1 \mathrm{vol} \%$, were dispersed in water at different $\mathrm{pH}$ values $\left(\mathrm{pH}_{\mathrm{i}}\right)^{2 \mathrm{II}}$ The suspension initially was turbomixed for $2 \mathrm{~h}$ and then aged for $30 \mathrm{~min}$, and the final $\mathrm{pH}$ values $\left(\mathrm{pH}_{\mathrm{f}}\right)$ of the suspension were measured; the results are shown in Table II. The suspensions, with $\mathrm{pH}_{\mathrm{i}}=6.76$, experienced minor changes in their $\mathrm{pH}_{\mathrm{f}}$ values after aging for $30 \mathrm{~min}$. However, the weakly acidic $\left(\mathrm{pH}_{\mathrm{i}}=\right.$ 3.2) or basic $\left(\mathrm{pH}_{\mathrm{i}}=10.1\right)$ suspensions approached a neutral condition. The change in the $\mathrm{pH}$ value $\left(\Delta \mathrm{pH}=\mathrm{pH}_{\mathrm{f}}-\mathrm{pH}_{\mathrm{i}}\right)$ becomes apparent if the concentration of TZP powder is larger (1 vol\%). A greater change in the content of $\mathrm{Y}_{2} \mathrm{O}_{3}$ powder,

\footnotetext{
IINote that $\mathrm{pH}_{\mathrm{i}}$ is different from $\mathrm{pH}_{0}$, because the powder surface reacts with the water.
}

Table II. Effect of Solids Loading on the pH of Various 3Y-TZP Solutions with Specified Acidity

\begin{tabular}{lccc}
\hline 3Y-TZP amount $(\mathrm{vol} \%)$ & $\mathrm{pH}_{\mathrm{i}}$ & $\mathrm{pH}_{\mathrm{f}}$ & $\Delta \mathrm{pH}$ \\
\hline 0.03 & 3.23 & 3.26 & 0.03 \\
0.1 & 3.23 & 3.47 & 0.24 \\
1 & 3.23 & 4.80 & 1.57 \\
0.03 & 6.76 & 6.84 & 0.08 \\
0.1 & 6.76 & 7.22 & 0.42 \\
1 & 6.76 & 7.11 & 0.35 \\
0.03 & 10.13 & 9.83 & -0.30 \\
0.1 & 10.13 & 8.88 & -1.25 \\
1 & 10.13 & 8.08 & -2.05 \\
\hline
\end{tabular}

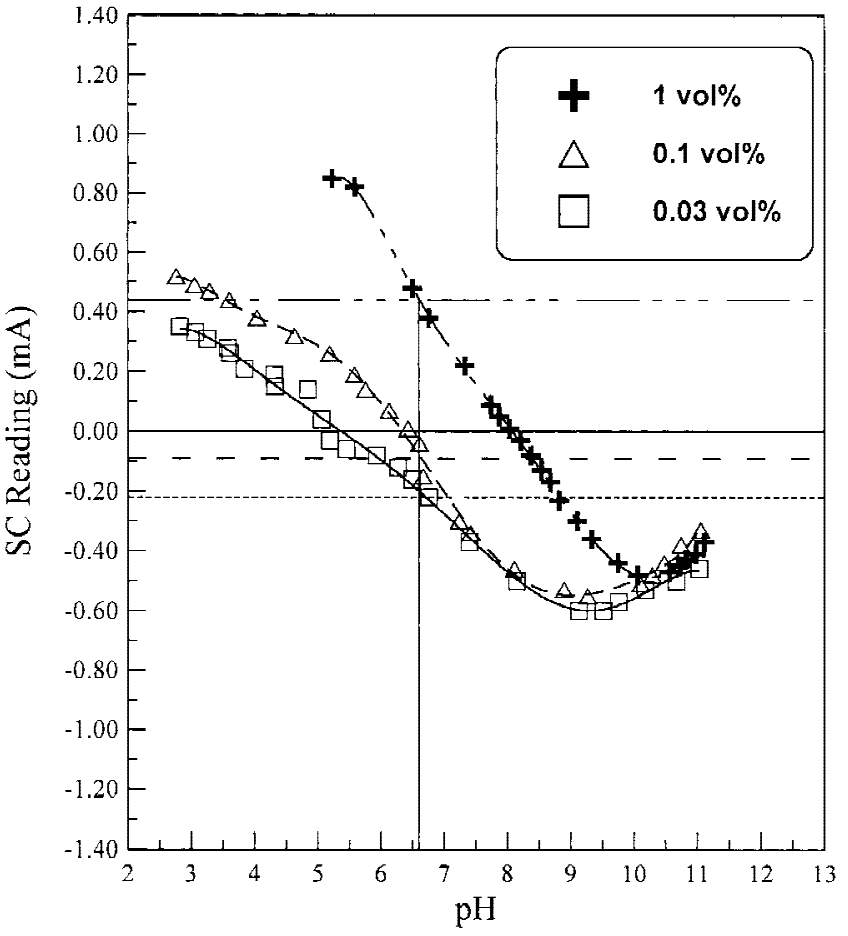

Fig. 4. Effect of $\mathrm{pH}$ and solids loading on the streaming-current (SC) reading of $3 \mathrm{Y}-\mathrm{TZP}$ suspensions with $0.01 M \mathrm{NaCl}$.

especially under acidic conditions $\left(\mathrm{pH}_{\mathrm{i}}=3.2\right)$, is noted in Fig. 1(b), where the acidity of the $\mathrm{Y}_{2} \mathrm{O}_{3}$ suspension changes by more than three orders of magnitude $(\Delta \mathrm{pH}=3.13)$. In other words, the hydration reaction of the $\mathrm{Y}_{2} \mathrm{O}_{3}$ and $3 \mathrm{Y}-\mathrm{TZP}$ powders is much stronger than that for pure $\mathrm{ZrO}_{2}$. This phenomenon is especially pronounced when the solids content of TZP powder in suspension is $>0.1 \mathrm{vol} \%$.

Figure 4 shows the $\mathrm{SC}$ reading versus the $\mathrm{pH}_{\mathrm{f}}$ values for $3 \mathrm{Y}$-TZP suspensions with a solids content of $0.03,0.1$, and 1 $\mathrm{vol} \%$. The dotted line at $-0.22 \mathrm{~mA}$ is the point of zero potential $(\zeta=0)$ for the suspension with a solids content of $0.03 \mathrm{vol} \%$. The IEP of the $3 \mathrm{Y}$-TZP should be intrinsically equal in the suspensions with solids content of $0.03,0.1$, or 1 vol\%. However, the $\mathrm{SC}$ reading changes according to the concentration of TZP powder $\left(C_{\mathrm{s}}\right)$, as shown in Eq. (A-3) in the Appendix. The apparent SC increases as the surface charge of TZP is relatively greater than the surface charge of the PTFE driver under various $\mathrm{pH}$ conditions. The results in Fig. 4 show that the SC measurement of the 3Y-TZP suspension apparently is affected by the powder content in suspension.

\section{(3) Influence of Electrolytes}

In this research, two types of electrolytes were dissolved in the zirconia solutions: $\mathrm{NaCl}$ salt, and ammonium molybdate $\left(\left(\mathrm{NH}_{4}\right)_{2} \mathrm{MoO}_{4}\right)$ that was prepared from the dissolution of molybdenum(VI) oxide $\left(\mathrm{MoO}_{3}\right)$ powder in a $5 \%$ ammonium $\left(\mathrm{NH}_{4}^{+}\right)$solution. Figure $5(\mathrm{a})$ plots the $\mathrm{SC}$ reading of the $3 \mathrm{Y}-\mathrm{TZP}$ suspension against the $\mathrm{pH}_{\mathrm{f}}$ value of the aqueous solutions; this figure indicates that $\mathrm{NaCl}$ can increase the ionic strength of the suspensions. The decrease in the surface potential of a highly electrolytic suspension $(0.1 M)$ has been reported as being due to compression of the double layer of ceramic particles. $^{13}$

In addition, the $\zeta$ value and acidity of the pure $\mathrm{ZrO}_{2}$ suspension are plotted as a function of the amount of $\mathrm{MoO}_{3}$ in Fig. 5(b). The molybdate ion $\left(\mathrm{MoO}_{4}^{2-}\right)$ can be formed when $\mathrm{MoO}_{3}$ is dissolved in an $\mathrm{NH}_{4}^{+}$solution. This figure shows that the $\mathrm{ZrO}_{2}$ surface seems to be negatively charged and the absolute values of $\zeta$ decrease as the $\mathrm{MoO}_{4}^{2-}$ concentration increase. In fact, the $\mathrm{OH}^{-}$and $\mathrm{MoO}_{4}^{2-}$ ions compete with each other to ad- 

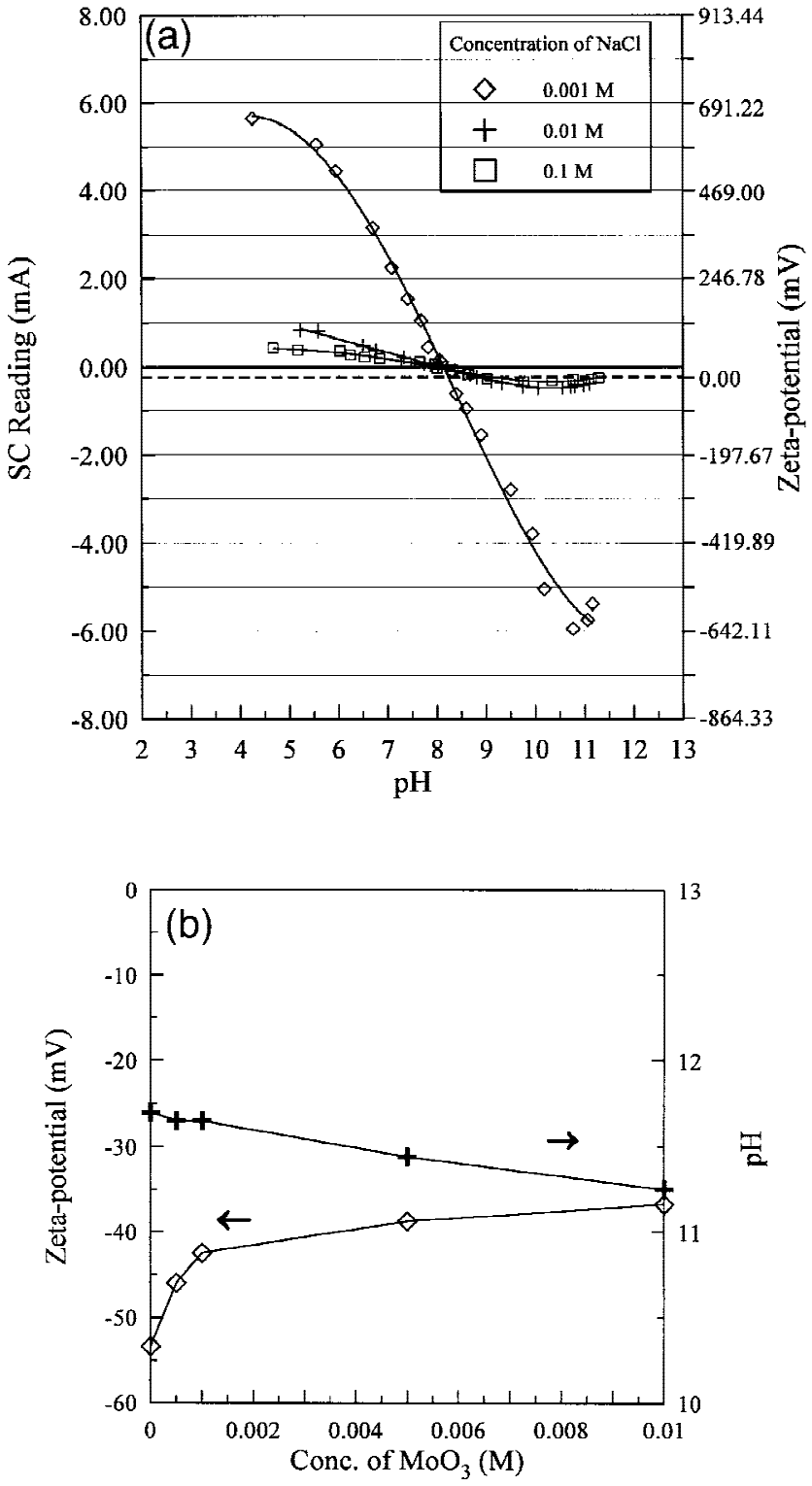

Fig. 5. (a) Streaming-current (SC) reading and zeta potential $(\zeta)$, relative to the $\mathrm{pH}$ of 1 vol\% 3Y-TZP suspensions with various $\mathrm{NaCl}$ concentrations; (b) $\zeta$ and $\mathrm{pH}$ of a pure $\mathrm{ZrO}_{2}$ suspension, relative to the amount of dissolved $\mathrm{MoO}_{3}$ in an ammonium suspension.

sorb onto the $\mathrm{ZrO}_{2}$ surface. The formation of a neutral site $\left(-\mathrm{MoO}_{2}\right)$ on the particles decreases the surface potential of the $\mathrm{ZrO}_{2}$. Thus, the surface charge of the $\mathrm{ZrO}_{2}$ particle can become less negative.

Figure 6 shows the effect of the polymeric dispersants D-134 and $\mathrm{B}-515.1$ on the $\mathrm{SC}$ and $\mathrm{pH}$ values of a $3 \mathrm{Y}-\mathrm{TZP}$ suspension with a solids content of $1 \mathrm{vol} \%$. The SC readings become negative when $>0.25 \mathrm{~mol} \%$ (based on solids content) of dispersant D-134 is used. Dissolution of dispersant D-134 in water seems to cause the charged backbone $\left(-[\mathrm{C}-\mathrm{COO}]_{n}-^{-}\right)$to be adsorbed on the particle surface, thus resulting in a reversal of surface potential. However, as the concentration of dispersant D-134 exceeds $1.0 \mathrm{~mol} \%$, the absolute value of the SC reading decreases slightly. This increase of the concentration of dissolved electrolyte results in compression of the double-layer thickness of $\mathrm{ZrO}_{2}$ particles; thus, the absolute values of the SC reading decrease accordingly. In contrast, dispersant B-515.1 has a weak electrostatic effect on the 3 Y-TZP powders (Fig. 6(b)), although the SC reading of the suspension exhibits almost no change. However, the $\mathrm{pH}$ changes slightly, from 5.2 to 4.4. This observation implies that more dispersant B-515.1 is

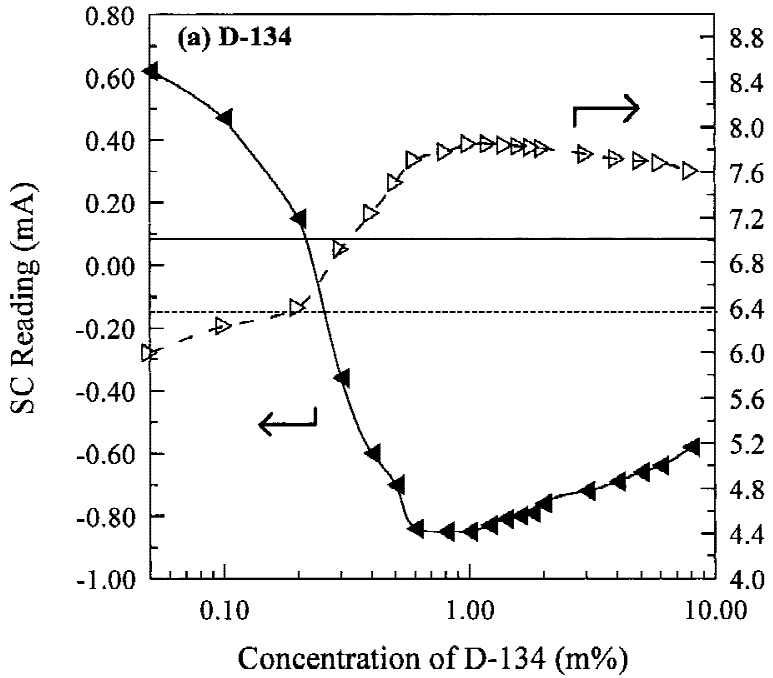

$\bar{a}$

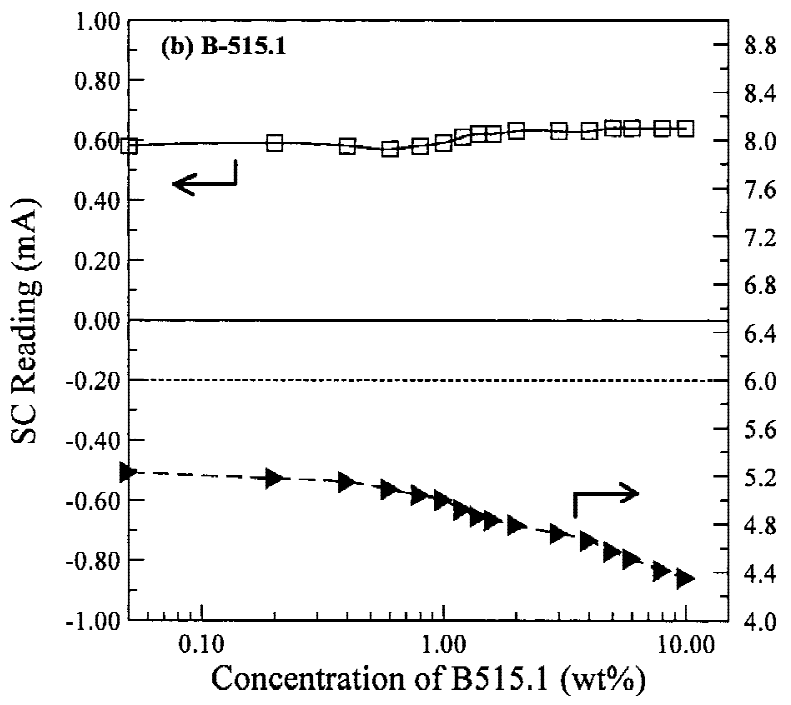

Fig. 6. Effects of dispersants ((a) D-134 and (b) B-515.1) on the streaming-current $(\mathrm{SC})$ reading and $\mathrm{pH}$ of a $3 \mathrm{Y}$-TZP suspension.

dissolving in the suspension as the concentration of dispersant B-515.1 increases, and few of the molecules are adsorbed on the TZP powder surface. The optimal dispersion effect of the $3 \mathrm{Y}$-TZP suspension could be produced by adding $1 \mathrm{~mol} \%$ of dispersant $\mathrm{D}-134$ under weakly basic conditions $(\mathrm{pH}=8-10)$.

The effect of $\mathrm{pH}$ on the SC of 3Y-TZP suspensions with a solids content of $1 \mathrm{vol} \%$ and 0 or $1 \mathrm{~mol} \%$ of dispersant D-134 are shown in Fig. 7. The dotted line in this figure represents an offset value of $0.44 \mathrm{~mA}$ for the suspension with $1.0 \mathrm{vol} \%$ of TZP (which has been used for SC measurement), as shown in Fig. 4. The IEP shifts from $\mathrm{pH} 6.6$ to $\mathrm{pH} 3.9$ as the additions of dispersant D-134 increase. In addition, SC readings of $3 \mathrm{Y}-$ TZP suspensions with high solids contents-2, 15, or $28 \mathrm{vol} \%$ (denoted as suspensions Z02D2, Z15D2 and Z2SD2, respectively) - also are shown in Fig. 7. The $\mathrm{pH}$ values of the latter three suspensions are in the range of 7.5-8.6; the higher the solids content, the lower the absolute value of the SC reading. The trend is similar to that observed in Fig. 3.

In contrast, the adsorption behavior of the polymeric chains on the surface of TZP is quite different from that of the $\mathrm{MoO}_{4}^{2-}$ ions. Dispersant D-134 is an anionic polymer with a 2-propenoic acid backbone; Fig. 8 shows that the adsorption isotherm of dispersant $\mathrm{D}-134$ onto a $\mathrm{ZrO}_{2}$ surface under various $\mathrm{pH}$ conditions is almost independent of the suspension $\mathrm{pH}$, over the $\mathrm{pH}$ range of 5-9. The adsorption results reveal that the 


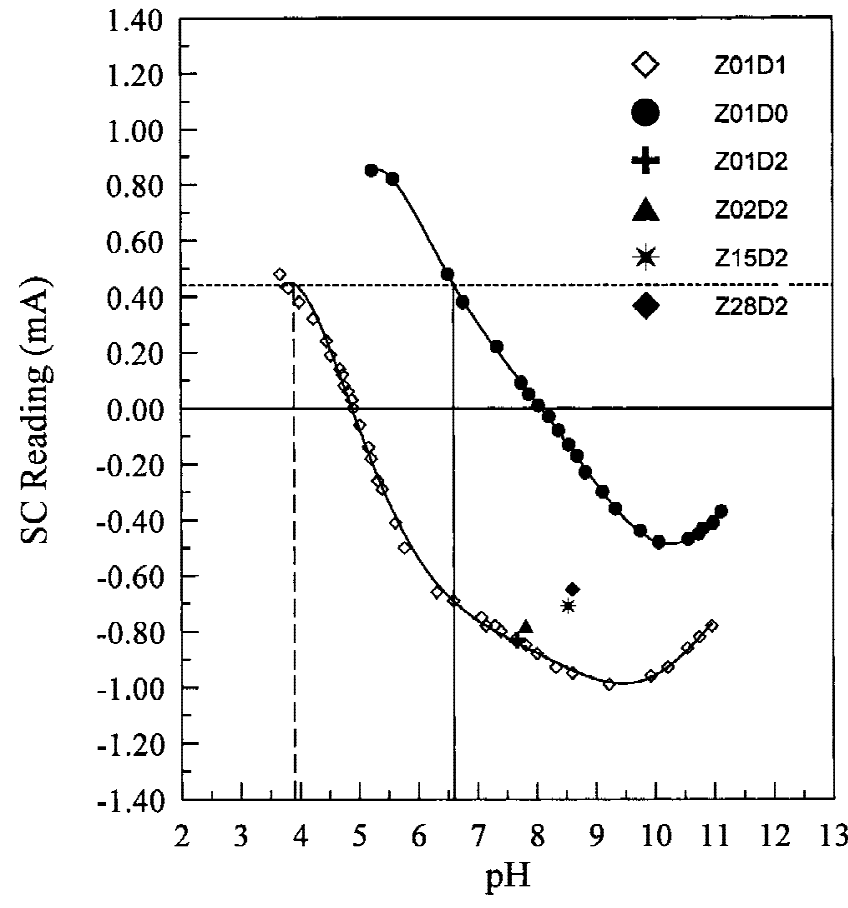

Fig. 7. Effect of $\mathrm{pH}$ on the streaming-current (SC) reading of $3 \mathrm{Y}$ TZP suspensions with various contents of solids and dispersant D-134. The format "ZxxDy" indicates the solids loading (xx vol\%) and the amount of added dispersant (y mol\%), based on the solid phase.

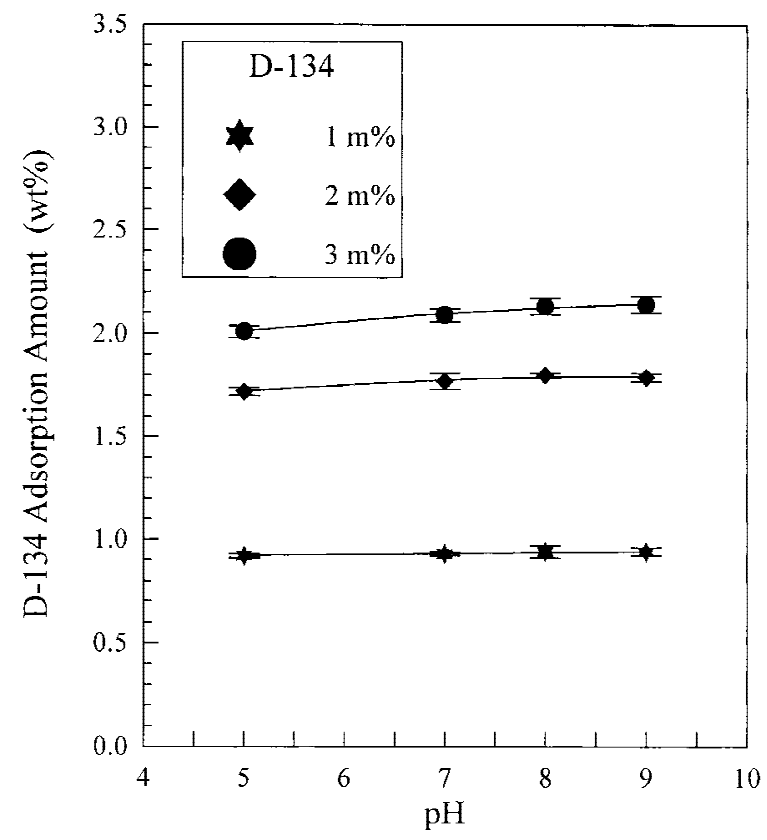

Fig. 8. Isothermic adsorption curves of various amounts of dispersant D-134 in a 3Y-TZP suspension with a solids content of $28 \mathrm{vol} \%$. Note that the amount of added dispersant D-134 in the suspension varied from $1 \mathrm{~mol} \%$ to $3 \mathrm{~mol} \%$, based on powder mass.

adsorbed amount of dispersant D-134 will increase as the amount of dispersant D-134 present in the $28 \mathrm{vol} \% 3 \mathrm{Y}$-TZP (Z2SD2) suspension increases. However, $1 \mathrm{~mol} \%$ of added dispersant D-134 has been adsorbed onto the powder surface, which yields a higher degree of absorption ( $90 \%)$ and a lower sensitivity to $\mathrm{pH}$. The degree of adsorption for the other two cases ( 2 and $3 \mathrm{~mol} \%$ of dispersant D-134 in the suspension) is only $85 \%$ and $70 \%$, respectively, and those cases are more sensitive to the suspension $\mathrm{pH}$. The dissolution coefficient of the polymeric dispersant D-134 should be lower under acidic conditions; thus, less dissolved molecules would be available to adsorb onto the TZP surface. The attached polymeric chains on the powder surface can lead the TZP particle to exert electrostatic stabilization.

\section{Discussion}

The surface of most oxide ceramics can react with water molecules at different rates, finally being converted to a hydrated layer when the particles are exposed to a humid atmosphere or an aqueous environment. ${ }^{1,4,5}$ The existence of a hydrated layer of tetragonal $\mathrm{ZrO}_{2}\left(t-\mathrm{ZrO}_{2}\right)$ has been proven using Fourier transform infrared (FTIR) spectroscopy techniques. ${ }^{5}$ The formation of a hydrated surface layer compensates for the unsaturated coordinative ions, because of breakage of the $\mathrm{Zr}-\mathrm{O}$ or $\mathrm{Y}-\mathrm{O}$ bonds. ${ }^{4}$ In an acidic solution, the $\mathrm{H}^{+}$cations in suspension are adsorbed onto the surface of $\mathrm{Y}_{2} \mathrm{O}_{3}$ or $\mathrm{ZrO}_{2}$ and produces a positively charged surface; however, the $\mathrm{Y}_{2} \mathrm{O}_{3}$ reaction proceeds fairly rapidly, with the complete reaction requiring $<10 \mathrm{~min}$. The $\mathrm{SC}$ data for $\mathrm{Y}_{2} \mathrm{O}_{3}$ in the $1.0 \mathrm{vol} \%$ suspension in Fig. 1(b) clearly indicates that the acidity of the suspension is balanced by this hydration reaction on the $\mathrm{Y}_{2} \mathrm{O}_{3}$ surface. Because of the adsorption of $\mathrm{H}^{+}$cations from the suspension, that $\mathrm{H}^{+}$concentration has been reduced by several orders of magnitude and consequently increases the $\mathrm{pH}$ of the $\mathrm{Y}_{2} \mathrm{O}_{3}$ suspension. A similar observation is presented in Table II, which shows the reaction of TZP powder with water; this effect is especially clear for highly concentrated suspensions.

The $\zeta$ value of a 3 Y-TZP suspension should be affected by the dissolved $\mathrm{Y}_{2} \mathrm{O}_{3}$ content. However, the shifting of the IEP toward a basic condition is not great enough to be detected via currently used techniques. The dissolution of $\mathrm{Y}_{2} \mathrm{O}_{3}$ or the hydration of oxide surfaces in the water has been reported in the literature. ${ }^{15,16} \mathrm{Y}_{2} \mathrm{O}_{3}$ has a tendency to produce a hydrated $\mathrm{Y}(\mathrm{OH})_{3}$ surface and dissolves in aqueous solution in the form of $\mathrm{Y}^{3+}, \mathrm{Y}(\mathrm{OH})^{2+}$, or $\mathrm{Y}_{2}(\mathrm{OH})_{2}^{4+}$ species. The reported equilibrium concentration of these hydrated yttria molecules is dependent on the $\mathrm{pH}$ conditions of the solution. ${ }^{15}$ Of these species, the $\mathrm{Y}^{3+}$ cation is the most concentrated species among these hydrates in solutions with $\mathrm{pH}<7.5$. The reported equilibrium concentration of $\mathrm{Y}^{3+}$ cations is $\sim 5 \times 10^{-4} \mathrm{~mol} / \mathrm{dm}^{3}$, which corresponds to a $\mathrm{Y}_{2} \mathrm{O}_{3}$ concentration of $\sim 0.11 \mathrm{~g} / \mathrm{dm}^{3}$. The $\mathrm{Y}^{3+}$ concentration is less than that in any TZP suspension with a solid TZP concentration of $>2.2 \mathrm{~g} / \mathrm{dm}^{3}$ (or $0.035 \mathrm{vol} \%$ ). As a result, the TZP suspension with a solids content of $0.03 \mathrm{vol} \%$ that is used to measure $\zeta$ may continue to dissolve $\mathrm{Y}^{3+}$ cations until an equilibrium concentration is achieved.

The zero SC reading of pure $\mathrm{ZrO}_{2}$ is located at $\mathrm{pH} 6.0$, which is less than the IEP values that have been reported in the literature $(\mathrm{pH}=6-6.7))^{3,4,6,8}$ There are two possible reasons for our lower measured values of $\mathrm{ZrO}_{2}$. The lower IEP value $(\mathrm{pH}=4.0$ or 5.0$)$ that was reported for the zirconia suspensions was perhaps due to the adsorption of a minor additive. The other possibility is the deviation (offset) of the SC reading from the $\zeta$ values. ${ }^{12}$ This observation would indicate that the $\zeta=0$ condition may result in an offset value of the SC reading $(-0.22 \mathrm{~mA})$, under various powder content levels in suspension, as proven in the Appendix.

Zirconia suspensions with a very minor amount $(3.3 \times$ $\left.10^{-4} M\right)$ of Dispex A40 dispersant or sodium sulfate $\left(\mathrm{Na}_{2} \mathrm{SO}_{4}\right)$ salt have lower IEP values. Leong and Boger $^{6}$ determined that the $\mathrm{SO}_{4}^{2-}$ ion is, in fact, adsorbed onto the surface of the $m$ phase powder; they also determined that the IEP value of the $\mathrm{ZrO}_{2}$ decrease as the powder concentration decreases. Figure 5 (b) reveals the effects of molybdate ions. Either $\mathrm{MoO}_{4}^{2-}$ or $\mathrm{Mo}_{7} \mathrm{O}_{24}^{6-}$ can be the ionic forms when $\mathrm{MoO}_{3}$ is dissolved in an $\mathrm{NH}_{4}^{+}$solution. The $\mathrm{MoO}_{4}^{2-}$ ions are stable in a basic $(\mathrm{pH}>7)$ solution. ${ }^{17}$ A previous study ${ }^{18}$ showed that the $\mathrm{MoO}_{4}^{2-}$ ion can be adsorbed onto the surface of alumina $\left(\mathrm{Al}_{2} \mathrm{O}_{3}\right)$ and the adsorption of the $\mathrm{MoO}_{4}^{2-}$ ion can shift the $\zeta$ value of the $\mathrm{Al}_{2} \mathrm{O}_{3}$ particle. Figure 5(b) shows that the $\mathrm{ZrO}_{2}$ surface seems to be 
negatively charged, and the absolute values of the $\zeta$ value decrease as the $\mathrm{MoO}_{4}^{2-}$ concentration increases. However, the $\mathrm{OH}^{-}$and $\mathrm{MoO}_{4}^{2-}$ ions compete with each other to adsorb onto the $\mathrm{ZrO}_{2}$. The adsorption of $\mathrm{MoO}_{4}^{2-}$ could release $\mathrm{OH}^{-}$ions concurrently, via the reaction

$$
\begin{aligned}
& \mathrm{Zr}-\mathrm{OH} \\
& \mathrm{Zr}-\mathrm{OH}
\end{aligned}+\mathrm{MoO}_{4}^{2-} \underset{\mathrm{Zr}-\mathrm{O}}{\leftarrow} \underset{\mathrm{Zr}-\mathrm{O}}{\leftarrow} \backslash \mathrm{MoO}_{2}+2 \mathrm{OH}^{-}
$$

The formation of a neutral site $\left(-\mathrm{MoO}_{2}\right)$ on the particles is attributed to the decrease of the surface potential of the $\mathrm{ZrO}_{2}$. If only a small amount of $\mathrm{MoO}_{4}^{2-}$ species is added, the surface potential of $\mathrm{ZrO}_{2}$ decreases and the surface of the $\mathrm{ZrO}_{2}$ particle shifts to a less-negative condition. However, the surface double layer is compressed if the $\mathrm{MoO}_{4}^{2-}$ concentration is $>0.01 M$, which ultimately may lead to particle agglomeration.

The interaction of polymeric dispersants with TZP powder in aqueous solution is clear. The SC curve (suspension Z01D1) is shifted from the position of the suspension Z01D0 curve to a negative value (Fig. 7) because of the adsorption of the ionized backbone of dispersant D-134. At the same time, the IEP of the colloidal system changes from 6.6 to 3.9. In addition, as the powder concentration increases (refer to the data points in Fig. 7 ), the absolute value of the corresponding $\zeta$ decreases slightly. The interparticle distance decreases as the solids content in the solution increases. Steric hindrance that results from the repulsion of adsorbed polymer on the TZP particle becomes apparent as the interparticle distance gets smaller. Therefore, the polymeric dispersant has an important role in the stabilization of zirconia suspensions (especially concentrated suspensions).

\section{Conclusions}

(1) Pure zirconia $\left(\mathrm{ZrO}_{2}\right)$ powder has an isoelectric point (IEP) in the $\mathrm{pH}$ range of 7.0-7.4. The zeta potential $(\zeta)$ and IEP of yttria-doped zirconia (Y-TZP) powders in a diluted suspension is hardly affected by the addition of yttria $\left(\mathrm{Y}_{2} \mathrm{O}_{3}\right)$. The IEP of Y-TZP powders with an $\mathrm{Y}_{2} \mathrm{O}_{3}$ content of 3-6 mol\% is in the $\mathrm{pH}$ range of 6.6-7.2.

(2) The streaming current (SC) and $\mathrm{pH}$ values of Y-TZP suspensions are strongly controlled by the powder content of the suspensions. This observation is related, in part, to the dissolution or hydration of $\mathrm{Y}_{2} \mathrm{O}_{3}$ on the surface of TZP under different $\mathrm{pH}$ conditions. The IEP shifts toward the IEP of $\mathrm{Y}_{2} \mathrm{O}_{3}$ as the TZP powder content in the suspension increases.

(3) The surface potential of $\mathrm{ZrO}_{2}$ is reduced because of the increased ionic strength of the suspension and/or the adsorption of molybdate $\left(\mathrm{MoO}_{4}^{2-}\right)$ ions onto the surface. A decrease of the absolute value of $\zeta$ for $\mathrm{ZrO}_{2}$ may result in the destabilization of $\mathrm{ZrO}_{2}$ particles in suspension when the concentration of electrolytes is $>0.1 M$.

(4) The polymeric dispersant D-134 is an effective dispersant for Y-TZP suspensions. The negatively charged polypropenoic acid backbone is adsorbed onto the particle surface in the $\mathrm{pH}$ range of 5-9. The degree of adsorption on TZP powder decreases from $90 \%$ to $70 \%$ as the addition of the dispersant increases from $1 \mathrm{~mol} \%$ to $3 \mathrm{~mol} \%$. The adsorption changes the IEP of the TZP powder to an acidic range $(\mathrm{pH}=3.9)$ and can offer electrosteric stabilization of zirconia powder in a weakly basic solution.

(5) Colloidal stability can be measured using either $\zeta$ or SC measurements. The relationship between these two parameters is linear in the $\mathrm{pH}$ range of 3-9. However, an offset from the origin of the current-potential $(I-\zeta)$ relationship is noted at the $\mathrm{SC}$ axis intercept at values that are dependent upon the powder concentration in suspension.

\section{APPENDIX \\ Relationship of the Streaming Current to the Zeta Potential of $\mathrm{ZrO}_{2}$ Powder}

The deviation of the streaming current (SC) reading from the zeta potential $(\zeta)$ that is shown in Fig. 3 implies that the surface charge of the SC detector (SCD) may contribute, in part, to the $\mathrm{SC}$ readings of charged $\mathrm{ZrO}_{2}$ particles in suspension. The suspension is flowing upward through the annulus when the piston is driving downward, as shown in Fig. A1(a). Thus, the net charge $q$ moving upward is given as

$$
\mathrm{d} q=\sigma_{\mathrm{s}} Q C_{\mathrm{s}} A_{\mathrm{s}}-\sigma_{\mathrm{p}} A_{\mathrm{p}}
$$

where $\sigma_{\mathrm{s}}$ and $\sigma_{\mathrm{p}}$ are the charge densities of the $\mathrm{ZrO}_{2}$ powder and the driving piston, respectively. $Q$ is the average flow volume of the suspension in the annulus of the SCD (in units of $\mathrm{dm}^{3}$ ), and $C_{\mathrm{s}}$ is the concentration of $\mathrm{ZrO}_{2}$ powder in suspension (in units of $\mathrm{g} / \mathrm{dm}^{3}$ ). $A_{\mathrm{s}}$ and $A_{\mathrm{p}}$ are the specific surface areas of the powder and the piston. $A_{\mathrm{p}}=2 \pi r \mathrm{~d} L$, where $L$ is the piston length. Thus, $Q$ then can be expressed as

$$
Q=-\pi r^{2} \mathrm{~d} L
$$

Combining Eqs. (A-1) and (A-2) and dividing by the change in time $\mathrm{d} t$ gives the instant current $I$ :

$$
I=\frac{\mathrm{d} q}{\mathrm{~d} t}=-\sigma_{\mathrm{s}} C_{\mathrm{s}} A_{\mathrm{s}} \pi r^{2} \frac{\mathrm{d} L}{\mathrm{~d} t}-\sigma_{\mathrm{p}}(2 \pi r) \frac{\mathrm{d} L}{\mathrm{~d} t}
$$

The charge densities $\sigma_{\mathrm{s}}$ and $\sigma_{\mathrm{p}}$ can be obtained because the surfaces of the powder and the piston hold an electric double layer. According to the Gouy-Chapman model, ${ }^{19}$ the average charge density is

$$
\sigma=\left(\frac{\varepsilon K T}{2 \pi z e \kappa^{-1}}\right) \sinh \left(\frac{z e \zeta}{2 k T}\right)
$$

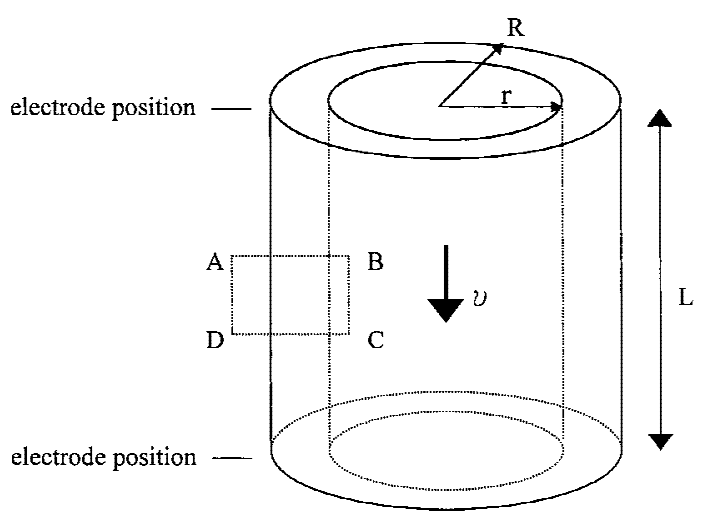

(a)

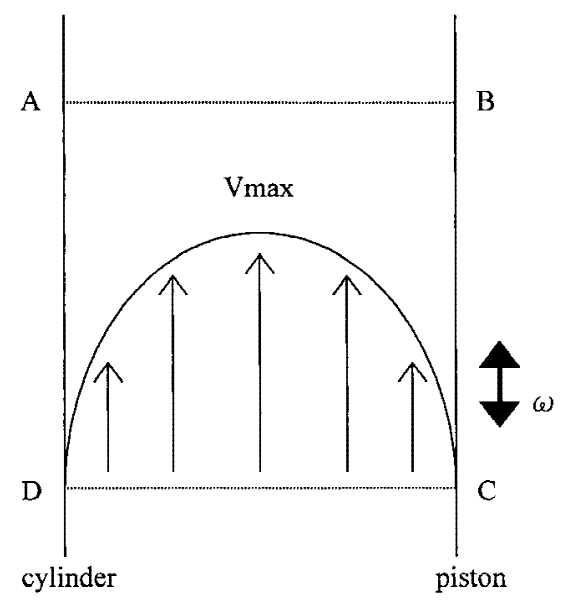

(b)

Fig. A1. Schematic diagrams of (a) a streaming-current detector (SCD) with downward piston motion and (b) the flow pattern of the suspension in the annulus. 
where $\varepsilon$ is the permittivity of water $\left(7.08 \times 10^{-10}\right), k$ the Boltzmann constant, $\zeta$ the electrokinetic potential of the $\mathrm{ZrO}_{2}$ particle, $z$ the valence number of predominant ions in solution (here, $z=1$ ), $e$ the electron charge, $T$ the absolute temperature, and $\kappa^{-1}$ the thickness of the double layer. Then, Eq. (A-4) can be simplified to Eq. (A-5) at low values of $\zeta$ and $\sigma$ :

$$
\sigma=\frac{\varepsilon \zeta}{4 \pi \kappa^{-1}}
$$

Equation (A-3) can be simplified to Eq. (A-6) when the geometric dimensions (here, $r=0.63 \mathrm{~cm}, R=0.645 \mathrm{~cm}$, and $L=2.45 \mathrm{~cm}$ ) of the instrument, the operation conditions (in this case, $\omega=4$ cycles per second), and the properties of the $3 \mathrm{Y}-\mathrm{TZP}$ powder (here, $A_{\mathrm{s}}=15.7 \mathrm{~m}^{2} / \mathrm{g}$ and $C_{\mathrm{s}}=10 \mathrm{~mol} / \mathrm{m}^{3}$ ) all are known:

$$
I=9.52 \times 10^{-3} \zeta_{\mathrm{s}}-3.21 \times 10^{-5} \zeta_{\mathrm{p}}
$$

and

$$
\sigma_{\mathrm{p}}=-1.29 \times 10^{-2} \zeta_{\mathrm{p}}=3.22 \times 10^{-3}\left[\frac{(R-r)^{2}}{\varepsilon \omega S}\right] I_{\mathrm{p}}
$$

By measuring the value of $I_{\mathrm{p}}$ for the polytetrafluorethylene (PTFE) material that comprises the plastic piston, the $\zeta_{\mathrm{p}}$ value that is calculated from Eq. (A-7) can be substituted into Eq. (A-6), giving

$$
I(\mathrm{~mA})=9.52 \times 10^{-3} \zeta_{\mathrm{s}}-0.128
$$

The second term of the right-hand side of Eq. (A-8) is -0.128 $\mathrm{mA}$, which is larger than, but on the same order as, the deviation value of the $(I-\zeta)$ diagram shown in Fig. $3(-0.221 \mathrm{~mA})$.

Acknowledgment: The authors express their appreciation for the kind discussion with Prof. Dahtong Ray (National Cheng-Kung University) on the measurement technique of organic concentrations in a solution.

\section{References}

${ }^{1}$ M. Obitsu, T. Kaga, and Y. Fujii, "Zirconia Sol and Method for Making the Same," U.S. Pat. No. 5223 176, Jan. 29, 1993.

${ }^{2}$ W.-C. J. Wei, S. J. Lu, and C. L. Hsieh, "Colloidal Processing and Fracture Strength of Alumina Prepared from Partially Agglomerated Theta-Phase Powder," J. Ceram. Soc. Jpn., 104 [4] 277-83 (1996).

${ }^{3}$ R. Moreno, J. Requena, and J. S. Moya, "Slip Casting of Yttria-Stabilized Tetragonal Zirconia Polycrystals," J. Am. Ceram. Soc., 71 [12] 1036-40 (1988).

${ }^{4}$ J. Wernet and D. L. Feke, "Effects of Solids Loading and Dispersion Schedule on the State of Aqueous Alumina/Zirconia Dispersions," J. Am. Ceram. Soc., 77 [10] 2693-98 (1994).

${ }^{5}$ C. Morterra, G. Cerrato, and L. Ferroni, "Surface Characterization of YttriaStabilized Tetragonal $\mathrm{ZrO}_{2}$, Part 1. Structural, Morphological, and Surface Hydration Features," Mater. Chem. Phys., 37, 243-57 (1994).

${ }^{6}$ Y. K. Leong and D. V. Boger, "Surface Chemistry and Rheological Properties of Zirconia Suspensions," J. Rheol. (NY), 35 [1] 149-65 (1991).

${ }^{7}$ Y. K. Leong, P. J. Scales, T. W. Healy, and D. V. Boger, "Effect of Particle Size on Colloidal Zirconia Rheology at the Isoelectric Point," J. Am. Ceram. Soc., 78 [8] 2209-12 (1995).

${ }^{8}$ M. Kagawa, M. Omori, and Y. Syono, "Surface Characterization of Zirconia after Reaction with Water," J. Am. Ceram. Soc., 70 [9] C-212-C-213 (1987).

${ }^{9}$ A. H. Heuer, "Transformation Toughening in $\mathrm{ZrO}_{2}$-Containing Ceramics," J. Am. Ceram. Soc., 70 [10] 689-98 (1987).

${ }^{10} \mathrm{~W}$. Huisman, T. Graule, and L. J. Gauckler, "Centrifugal Slip Casting of Zirconia (TZP)," J. Eur. Ceram. Soc., 13, 33-39 (1994).

${ }^{11}$ P. C. Hiemenz, Principles of Colloidal and Surface Chemistry. Marcel Dekker, New York, 1977.

${ }^{12}$ S. K. Dentel and K. M. Kingery, "Theoretical Principles of Streaming Current Detection," Water. Sci. Technol., 21, 443-53 (1989).

${ }^{13}$ S. K. Dentel, A. V. Thomas, and K. M. Kingery, "Evaluation of the Streaming Current Detector, I. Use in Jar Test," Water. Sci. Technol., 21, 413-21 (1989).

${ }^{14} \mathrm{H}$. Shan and Z. Zhang, "Slip Casting of Nanometer Sized Tetragonal Zirconia Powder," Br. Ceram. Trans., 95 [1] 35-38 (1996).

${ }^{15}$ M. Yasrebi, M. Z. Moroz, W. Kemp, and D. H. Sturgis, "Role of Particle Dissolution in The Stability of Binary Yttria-Silica Colloidal Suspensions," $J$. Am. Ceram. Soc., 79 [5] 1223-27 (1996).

${ }^{16}$ M. Yasrebi, M. E. Springgate, D. G. Nikolas, W. Kemp, and D. H. Sturgis, "Colloidal Stability of Zirconia-Doped Yttria-Silica Binary Aqueous Suspensions," J. Am. Ceram. Soc., 80 [6] 1615-18 (1997).

${ }^{17}$ N. P. Lutra and W. C. Cheng, "Molybdenum-95 NMR Study of the Adsorption of Molybdate on Alumina," J. Catal., 107, 154-60 (1987).

${ }^{18}$ M. H. Lo, F. H. Cheng, and W. J. Wei, "Preparation of $\mathrm{Al}_{2} \mathrm{O}_{3} / \mathrm{Mo}$ Nanocomposite Powder via Chemical Route and Spray Drying," J. Mater. Res. 11 [8] 2020-28 (1996).

${ }^{19}$ R. J. Hunter, Foundations of Colloidal Science, Vol. 1. Clarendon Press, Oxford, U.K., 1992. 